\title{
Epidemiology of tuberculosis and evaluation of treatment outcomes in the national tuberculosis control programme, River Nile state, Sudan, 2011-2013
}

W.M. Elmadhoun, ${ }^{1}$ S.K. Noor, ${ }^{7}$ S.O. Bushara, ${ }^{7}$ E.O. Ahmed, ${ }^{2}$ H. Mustafa, ${ }^{3}$ A.A. Sulaiman, ${ }^{7}$ A.O. Almobarak ${ }^{4}$ and M.H. Ahmed $^{5}$

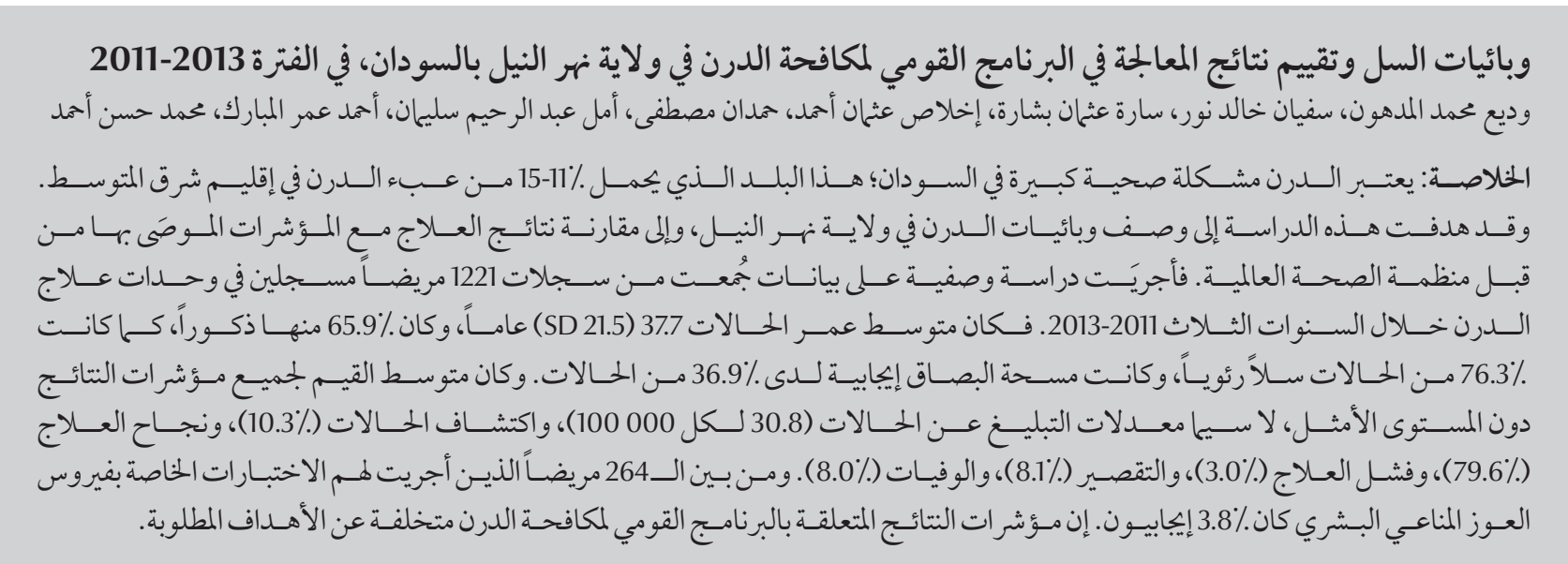

ABSTRACT Tuberculosis is a major health problem in Sudan, a country that carries 11-15\% of the tuberculosis burden in the Eastern Mediterranean Region. This study aimed to describe the epidemiology of tuberculosis in River Nile State and to compare treatment outcomes with WHO recommended indicators. A descriptive study was conducted on data collected from records of 1221 patients registered at tuberculosis management units over the 3 years $2011-$ 2013. The mean age of cases was 37.7 (SD 21.5) years and 65.9\% were males; $76.3 \%$ were pulmonary tuberculosis and $36.9 \%$ were sputum smear-positive cases. Average values for all outcome indicators were suboptimal, notably rates of case notification (30.8 per 100 000), case detection (10.3\%), treatment success $(79.6 \%)$, treatment failure (3.0\%), default (8.1\%) and death (8.0\%). Of the 264 patients tested for HIV, 3.8\% were positive. Outcome indicators for the national tuberculosis control programme are lagging behind the required targets.

Épidémiologie de la tuberculose et évaluation des résultats du traitement dans le cadre d'un programme national de lutte antituberculeuse, État du Nil (Soudan), 2011-2013

RÉSUMÉ La tuberculose est un problème de santé majeur au Soudan où elle représente 11 à 15 \% de la charge de la maladiedanslaRégion delaMéditerranéeorientale.Laprésenteétudeavaitpourobjectifdedécrirel'épidémiologie de la tuberculose dans l'État du Nil et de comparer les résultats du traitement à l'aide d'indicateurs recommandés par l'OMS. Une étude descriptive a été menée à partir de données extraites des dossiers de 1221 patients admis dans des unités de prise en charge de la tuberculose sur une période de trois ans (2011-2013). L'âge moyen des cas était de 37,7 ans (ET 21,5) et 65,9\% étaient de sexe masculin ; 76,3\% étaient atteints de tuberculose pulmonaire et 36,9 \% étaient des cas à frottis positifs. Les valeurs moyennes pour tous les indicateurs de résultats étaient sous-optimales, notamment les taux de notification (30,8 pour 100 000), de dépistage de cas $(10,3 \%)$, de guérison $(79,6 \%)$, d'échec thérapeutique (3,0\%), d'abandon $(8,1 \%)$ et de décès $(8,0 \%)$. Sur les 264 patients dépistés pour le VIH, 3,8 \% étaient positifs. Les indicateurs de résultats pour le programme national de lutte antituberculeuse accusent un retard par rapport aux objectifs fixés.

${ }^{7}$ Nile Valley University, Atbara, Sudan (Correspondence to W.M. Elmadhoun: wadie2222@yahoo.com). ${ }^{2}$ National Tuberculosis Control Programme, River Nile State, Atbara, Sudan. ${ }^{3}$ National Tuberculosis Control Programme, Khartoum, Sudan. ${ }^{4}$ University of Medical Sciences and Technology, Khartoum, Sudan. ${ }^{5}$ Department of Medicine, Milton Keynes University Hospital NHS Foundation Trust, Milton Keynes, United Kingdom.

Received: 26/01/15; accepted: 15/11/15 


\section{Introduction}

Tuberculosis remains a major cause of morbidity and mortality in many developing countries. In 2012, there were 8.6 million new tuberculosis cases and 1.3 million deaths due to tuberculosis worldwide (1). An estimated $95 \%$ of tuberculosis cases and $98 \%$ of deaths due to tuberculosis occur in developing countries (2). Sudan alone carries $11-15 \%$ of the tuberculosis burden in the Eastern Mediterranean Region (EMR). The estimated incidence of new tuberculosis cases in 2010 was 119 per 100000 population, and the estimated prevalence was 209 per 100000 , causing an overall death rate of 24 per 100000 annually (3).

The national tuberculosis control programme in Sudan is working on many aspects of control, including the care and management of patients and the reduction of risk for others. However, many challenges exert a negative impact on tuberculosis control performance, including, but not limited to, the ongoing civil war, internal displacement, poor nutrition, poverty, overcrowding, HIV infection and chronic debilitating diseases.

The tuberculosis control programme in River Nile state was established 1997. The outcome of the programme needs to be documented and evaluated periodically to check its progress, as recording and reporting of treatment outcomes is one of the 5 elements of the directly observed treatment, short-course (DOTS) strategy and the updated version of the World Health Organization's (WHO) Stop TB strategy $(4,5)$. It is essential to determine the epidemiological situation to better understand the disease. The aim of this study therefore was to document the epidemiology of tuberculosis patients treated under the DOTS strategy in River Nile state, Sudan, and to evaluate the treatment outcome indicators of the national tuberculosis control programme compared with WHO recommended targets.

\section{Methods}

\section{Setting}

River Nile state lies in northern Sudan $\left(32^{\prime} 36^{\circ} \mathrm{N}\right.$ and $\left.16^{\prime} 22^{\circ} \mathrm{E}\right)$ and has an area of $124000 \mathrm{~km}^{2}$ with a population of about 1250000 from different ethnic groups. The most important cities are El Damer, Atbara, Shendi and Abu Hamad. There are 13 tuberculosis management units where suspected tuberculosis patients are diagnosed and treated. The units have medical and nursing staff and social workers and are integrated within the general health system and distributed over the 7 districts of the state

Ethical approval for the study was obtained from the ethics committee of the Faculty of Medicine at Nile Valley University. This work was conducted with the collaboration and supervision of the Ministry of Health, River Nile state.

\section{Data collection tools}

Data were collected from the tuberculosis records at tuberculosis management units. The records include the following epidemiological, clinical and microbiological data: name, age, sex, residence, centre of diagnosis and management, referral source, date of presentation, site of disease, signs and symptoms with duration, whether new or re-treatment case, sputum microscopy tests initially and periodically, other diagnostic methods, treatment category, time of sputum conversion, treatment outcomes and HIV status. The recording and reporting of registered cases has been improving in recent years and the best records available were selected for this study.

\section{Case definitions}

In River Nile state, tuberculosis is diagnosed using patient history, clinical examination and diagnostic tests, including sputum microscopy, chest Xray and tissue samples.

World Health Organization (WHO) case definitions and methods of calculating indicators for the monitoring and evaluation of tuberculosis control programmes were used in this study (3).

In Sudan, the national tuberculosis control programme is based on the passive and voluntary case approach, i.e. no active search for suspected tuberculosis cases or contacts, and compliance with treatment is optional. For instance, the index tuberculosis case is asked to register and invite individuals in contact with him/her for further assessment and possible prophylaxis or treatment in the tuberculosis management unit; however, there is no obligation for registration or for assessment.

\section{Data analysis}

A descriptive analysis for the selected variables was performed using SPSS computer program, version 20.0. The frequency distribution of the different variables and the percentages of cases with data on these variables were calculated. Age was characterized by mean and standard deviation (SD). $P$-value $<0.05$ was considered statistically significant for comparing proportions.

\section{Results}

\section{Treatment success rates of tuberculosis cases, 2002-2013}

Figure 1 documents the number of tuberculosis cases and treatment success rates in River Nile state from the year 2002 to 2013. Over the 12-year period, the total number of registered cases ranged between 364 and 527, with a slight decreasing trend. Moreover; the treatment success rate during the same period ranged between $66.9 \%$ and 89.3\%, with fluctuations among various years. 


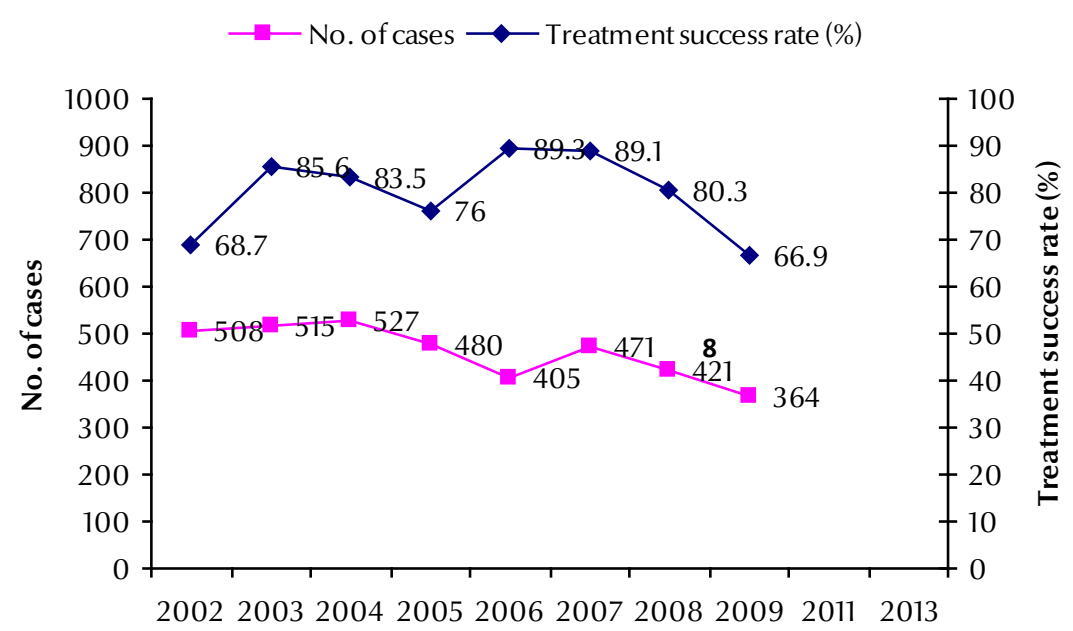

Figure 1 Annual number of registered cases and treatment success rates for tuberculosis patients in River Nile state, Sudan, 2002-2013

\section{Demographic characteristics of tuberculosis cases, 2011- 2013}

The remainder of the analysis was for data from the 3-year period 2011-13. The total number of cases notified during the study period was 1221, distributed almost equally across the 3 years. There were 805 males and 416 females (male to female ratio of 2:1). The most common age groups affected (58.5\%) were the young and middle-age adults aged $16-50$ years, whereas children aged $0-15$ years constituted $14.0 \%$ of cases (Table 1).

The districts of residence of tuberculosis patients are shown in Table 2; sporadic cases were reported from every district in River Nile state. While the highest proportion of tuberculosis cases (29.3\%) came from El Damer district, most cases (40.4\%) were diagnosed and managed in Atbara hospital (Table 1). Most tuberculosis patients $(73.6 \%)$ were referred to the tuberculosis management unit from a government health unit, some patients (11.0\%) notified directly to the tuberculosis management unit suspecting themselves of having tuberculosis, and only $0.4 \%$ were notified by other community members (Table 1).

\section{Clinical characteristics of tuberculosis cases, 2011-2013}

While most patients enrolled in the DOTS strategy were new cases of tuberculosis (84.3\%), a considerable percentage ( $8.2 \%$ ) was defaulters, relapses and treatment failures (Table 2).

Cough and fever with sweating were the most common presenting clinical features, Table 3 . The duration between onset of symptoms and presentation to the tuberculosis management unit in most cases (66.3\%) was 4-12 weeks; however $11.4 \%$ presented very late, i.e. 1 year or more after the onset of symptoms (Table 2). Most cases were in treatment category 1 (88.4\%) and only $11.6 \%$ were category 2 . There was no significant variation in disease distribution across quarters and months of the year (data not shown).

\section{Tuberculosis control programme indicators, 2011-2013}

Table 4 shows the national tuberculosis control programme outcome indicators for each year and the averages over the 3-year period 2011-13. When compared with WHO targets, all monitoring and evaluation indicators for River Nile state fell behind the targets. Of concern were the low notification rate (30.8 per 100000 population) and case detection rates. There were very few new sputum smear-positive cases (10.3\%), which lowered the rates of other indicators that depend on calculation of smear-positive cases. Culture services are not available in River Nile state and therefore not a single case had a culture result. The 3 -year average sputum conversion rate at the end of the initial phase of treatment was $61.9 \%$. Other figures were: treatment success rate $79.6 \%$, cure rate $51.6 \%$, treatment completion rate $34.0 \%$, treatment failure rate $3.0 \%$ and default rate $8.1 \%$.

The average death rate over the 3 years was $8.0 \%$. The death rate among males was 9.2\% (74/805) and among females was 7.0\% (29/416), although this difference was not statistically significant $(P=0.18)$. The death rates were significantly higher at the extremes of age: $23.1 \%$ among children aged $<1$ year and $18.5 \%$ for adults aged $>50$ years compared with $3.8-5.2 \%$ among other age groups $(P<0.001)$. The death rate among pulmonary tuberculosis cases was 9.1\% (85/932) versus 6.2\% $(18 / 289)$ among extrapulmonary cases $(P=0.18)$.

\section{HIV tuberculosis co-infection}

HIV testing was voluntary and only 264 (21.6\%) cases were tested for HIV. Ten of them (3.8\%) tested positive for the virus. The death rate was $20.0 \%(2 / 10)$ among HIV-positive tuberculosis cases compared with 6.3\% (16/254) among those who tested negative for HIV, and $8.9 \%(85 / 957)$ among those not tested $(P=0.002)$ (Table 4).

\section{Discussion}

This study documents the characteristics of tuberculosis patients, treatment outcome and the infection control indicators for assessment of the tuberculosis control programme in River Nile State over 2011-2013. To our best of knowledge, this is the first such study in Sudan. 
The annual incidence of tuberculosis remained more or less constant, which may indicate a stabilization of tuberculosis endemicity. The annual notification rate in River Nile state was low (30.8 per 100000 ), i.e. around 400 cases per year. According the annul risk of infection in Sudan that considers the estimated notification rate should be around 119 new cases for every 100000 population per year, our state should notify about 1500 per year. This low detection rate may be attributed to the fact that more tuberculosis cases are not notified or that tuberculosis is less prevalent in this state compared with rest of the country. This finding necessitates active surveillance for tuberculosis in the community rather than waiting for patients to voluntarily visit health facilities.

Over the 3-year period there was a similar number of cases each year, indicating the static state of case notifications for tuberculosis in River Nile state. This may suggest again that more efforts are needed by the national control programme to increase the case detection rate. The distribution of cases during the months of the year was also similar, reflecting the absence of seasonal variation or climatic effect on tuberculosis; or perhaps that health seeking-behaviour in the region is not affected by climate.

Nearly half of the patients were diagnosed in Atbara teaching hospital. This may be explained by the fact that Atbara is the largest tertiary hospital in River Nile state. However, the lower number of patients diagnosed and managed in the other tuberculosis management units may reflect less-than-optimal services provided by these centres or by a lack of trained health personnel.

Males constituted almost two-thirds of tuberculosis patients. This is similar to the global ratio reported by WHO (6) and the findings of other studies $(7,8)$. This male predilection may be explained by the habit of smoking that is more common in males, by different

\begin{tabular}{|c|c|c|}
\hline Variable & No. & $\%$ \\
\hline \multicolumn{3}{|l|}{ Sex } \\
\hline Male & 805 & 65.9 \\
\hline Female & 416 & 34.1 \\
\hline \multicolumn{3}{|l|}{ Age group (years) } \\
\hline$\leq 5$ & 94 & 7.7 \\
\hline $6-15$ & 77 & 6.3 \\
\hline $16-30$ & 364 & 29.8 \\
\hline $31-50$ & 350 & 28.7 \\
\hline$>50$ & 336 & 27.5 \\
\hline \multicolumn{3}{|l|}{ District of residence } \\
\hline El Damer ${ }^{a}$ & 358 & 29.3 \\
\hline Atbara $^{\mathrm{b}}$ & 281 & 23.0 \\
\hline Shendi ${ }^{\mathrm{c}}$ & 274 & 22.4 \\
\hline Berber $^{d}$ & 200 & 16.4 \\
\hline Abu Hamad and Elbuhaira ${ }^{e}$ & 86 & 7.0 \\
\hline Elmatama $^{f}$ & 12 & 0.8 \\
\hline \multicolumn{3}{|l|}{ Source of referral } \\
\hline Governmental health unit & 899 & 73.6 \\
\hline Private clinic & 167 & 13.7 \\
\hline Patient him/herself & 134 & 11.0 \\
\hline Community & 5 & 0.4 \\
\hline \multicolumn{3}{|l|}{ Tuberculosis management unit } \\
\hline Atbara teaching hospital & 493 & 40.4 \\
\hline Shendi teaching hospital & 293 & 24.0 \\
\hline El Damer teaching hospital & 159 & 13.0 \\
\hline Berber teaching hospital & 102 & 8.3 \\
\hline Abu Hamad hospital & 63 & 5.2 \\
\hline Police and military hospitals (Atbara) & 40 & 3.3 \\
\hline $\begin{array}{l}\text { Other: Ameky, Kadabas, Sidon, Kurgus, } \\
\text { Elbasabir, Elketayab }\end{array}$ & 71 & 5.8 \\
\hline
\end{tabular}

${ }^{a}$ El Damer city, Nahr Atbara, Elzaidab, Elhasaya, Elmanasir, Elmakabrab; ${ }^{b}$ Khelaiwa, Elwihda, Hay Alarab, Hay Elmatar, Elshargy, Elmorada; 'Shendi city, Guraish, Elshagalwa, Kaboshia; ${ }^{d} B e r b e r$ city, Kanoor, Elmakaylab, Elbawga, Dar Maly; ${ }^{e}$ Nagaso Ashawa, Eltawaheen, Korgus; ${ }^{;}$Elmatama city.

immunological factors, by greater outdoor exposure to infected individuals among men or by other unknown factors. It is important to note that issues of variation in accessibility, health-seeking behaviour and gender discrimination are not encountered in the communities of River Nile state, as males and females are equally treated when sick (authors' observations).

The age groups most commonly affected by tuberculosis were adults in their productive years, a finding that is similar to other studies (2), and this age group also coincides with the peak age group for HIV infection worldwide (6).

Most patients were referred from government-run health units (73.6\%) and only a low number from private clinics. This may be an indication of the low socioeconomic status of patients. An even smaller number presented directly to the tuberculosis management unit $(11.0 \%)$ or were notified by a member of the community $(0.4 \%)$. This finding may reflect the low awareness in 


\begin{tabular}{|c|c|c|}
\hline Characteristic & No. & $\%$ \\
\hline \multicolumn{3}{|c|}{ Type of TB patient at start of treatment } \\
\hline New case & 1030 & 84.3 \\
\hline Relapse & 49 & 4.0 \\
\hline Transferred & 13 & 1.1 \\
\hline Defaulter & 44 & 3.6 \\
\hline Treatment failure & 7 & 0.6 \\
\hline Other type ${ }^{\mathrm{a}}$ & 78 & 6.4 \\
\hline \multicolumn{3}{|l|}{ Site of TB } \\
\hline Pulmonary & 932 & 76.3 \\
\hline Extrapulmonary & 289 & 23.7 \\
\hline Sputum-positive for AFB & 344 & $36.9^{c}$ \\
\hline \multicolumn{3}{|l|}{ Symptoms } \\
\hline Cough & 741 & 79.5 \\
\hline Fever and sweating & 817 & 66.9 \\
\hline Chest pain & 34 & 2.8 \\
\hline Loss of weight & 145 & 11.9 \\
\hline Diarrhoea & 29 & 2.4 \\
\hline Lymphadenopathy & 65 & 5.3 \\
\hline Cold abscess & 16 & 1.3 \\
\hline Other symptoms ${ }^{b}$ & 141 & 11.5 \\
\hline \multicolumn{3}{|l|}{ Duration of symptoms } \\
\hline 1-3 weeks & 189 & 15.5 \\
\hline 4-6 weeks & 359 & 29.4 \\
\hline 7-12 weeks & 451 & 36.9 \\
\hline 1 year & 91 & 7.5 \\
\hline$>1$ year & 48 & 3.9 \\
\hline Unknown & 83 & 6.8 \\
\hline \multicolumn{3}{|l|}{ Treatment category } \\
\hline Category 1 & 1079 & 88.4 \\
\hline Category 2 & 142 & 11.6 \\
\hline
\end{tabular}

${ }^{a}$ Other types included: symptomatic cases, sputum-negative cases, cases previously treated, patients not known to be treated or of unknown outcome, or patients returned to treatment from pulmonary tuberculosis negative or extrapulmonary tuberculosis.

${ }^{b}$ Other symptoms included: discharging sinus, paraplegia, abdominal pain general ill-health, etc.; $c \%$ of pulmonary tuberculosis cases.

$T B=$ tuberculosis; $A F B=$ acid-fast bacilli.

our community about the symptoms of the disease or low awareness about the existence of the tuberculosis management unit.

Despite the fact that tuberculosis was prevalent in most geographical areas of River Nile state, there were certain foci where the disease was more prevalent. This may be due to socioeconomic, familial or genetic factors that potentiate disease dissemination, a finding that may help health planners to target certain populations for control activities. The variation in the number of tuberculosis patients among different localities may be due to differences in socioeconomic status or it may reflect different levels of awareness about tuberculosis or variations in health-seeking behaviour. The areas with fewest patients may alternatively be an indication of the lack of health services or lack of accessibility to services in these areas.

Cough, fever and night sweating were the main symptoms for most patients. The duration of the symptoms varied from 1 week up to more than 1 year, with a peak around 7-12 weeks. This late presentation may be attributed to low awareness about tuberculosis in our community, or to a low index of suspicion for tuberculosis among health workers. Stigma about tuberculosis may also be a factor, if neither patients nor caregivers wish to attribute the symptoms of chronic cough, fever, etc. to tuberculosis at the first visit. Tuberculosis is usually suspected and investigated when no response is seen after many trials of antibiotics and cough medications. Therefore, both health system delay and patient delay are likely to play a role in this regard.

Concerning the site of the disease, pulmonary tuberculosis was the predominant type, a finding that is consistent with many other reports $(2,7,9)$. The major sites for extrapulmonary tuberculosis, as clinically encountered, are the lymph nodes, abdomen and less commonly bones and joints. However, no details about the site involved are documented in the Sudan national tuberculosis control programme registries.

Most of the patients in our survey were treated according to category 1 . However, the number of those in category 2 is alarming. Category 2 patients include relapse and default cases, a focus of concern for emergence of multidrugresistant tuberculosis cases.

Treatment outcomes are an important indicator of the performance of any tuberculosis control programme. Despite the fact that most tuberculosis patients on DOTS in our survey were new cases, the percentage of relapsed, failure and default cases found were relatively high $(4.0 \%, 3.0 \%$ and $8.1 \%$ respectively), constituting a threat to the community, as these cases are 


\begin{tabular}{|c|c|c|c|c|c|}
\hline \multirow[t]{2}{*}{ Indicator } & \multirow[t]{2}{*}{ WHO target } & \multicolumn{4}{|c|}{ River Nile state } \\
\hline & & $\begin{array}{c}2011 \\
(n=397)\end{array}$ & $\begin{array}{c}2012 \\
(n=391)\end{array}$ & $\begin{array}{c}2013 \\
(n=433)\end{array}$ & $\begin{array}{l}\text { 3-year average } \\
(n=1221)\end{array}$ \\
\hline $\begin{array}{l}\text { Case notification rate of all forms of TB (per } 100000 \\
\text { population) }\end{array}$ & 119 & 26.6 & 31.3 & 34.6 & 30.8 \\
\hline Case detection rate-new smear-positive TB cases (\%) & 50 & 10.0 & 11.3 & 9.6 & 10.3 \\
\hline $\begin{array}{l}\text { Case detection rate-new smear-positive pulmonary } \\
\text { TB cases }(\%)\end{array}$ & 65 & 27.6 & 39.9 & 28.9 & 32.1 \\
\hline $\begin{array}{l}\text { Sputum conversion rate at end of initial phase of } \\
\text { treatment }(\%)\end{array}$ & 90 & 64.3 & 54.7 & 66.7 & 61.9 \\
\hline New extrapulmonary TB cases (\% of all TB) & $<15$ & 25 & 25.2 & 26.1 & 25.4 \\
\hline Retreatment TB cases $(\%)$ & 7 & 7.0 & 10.2 & 6.2 & 7.8 \\
\hline Treatment success rate $(\%)$ & 90 & 82.1 & 79.0 & 77.8 & 79.6 \\
\hline Cure rate (\%) & 85 & 50.0 & 57.9 & 46.9 & 51.6 \\
\hline Treatment completion rate (\%) & 85 & 32.1 & 21.1 & 30.9 & 34.0 \\
\hline Death rate $(\%)$ & 3 & 8.3 & 8.4 & 7.4 & 8.0 \\
\hline Treatment failure rate $(\%)$ & 1 & 1.2 & 4.2 & 3.7 & 3.0 \\
\hline Default rate (\%) & 4 & 6.0 & 8.4 & 9.9 & 8.1 \\
\hline Transfer-out rate (\%) & 1 & 3.6 & 4.2 & 4.9 & 4.2 \\
\hline TB cases tested for HIV (\%) & 100 & 8.8 & 22.5 & 32.6 & 21.3 \\
\hline HIV seroprevalence among TB cases (\%) & - & 11.4 & 4.5 & 1.4 & 5.8 \\
\hline $\begin{array}{l}\text { Coverage of TB management units (per } 50 \text { 000-100 } 000 \\
\text { population) }\end{array}$ & 13 & 10 & 13 & 14 & 12 \\
\hline
\end{tabular}

liable to develop multidrug resistance. Non-compliance with medication may be partially attributed to health workers' poor communication skills with patients. For instance, tuberculosis patients in our health facilities are generally told that they have some sort of a chronic chest infection and not frankly informed about tuberculosis. This inappropriate labelling of patients could result in discontinuation of medications once symptoms are alleviated. The relatively long duration of tuberculosis treatment may constitute an obstacle to compliance.

Only about one-third of pulmonary tuberculosis patients in this survey (32.1\%) were sputum smear-positive. This indicates that the diagnostic capacity of the programme needs further work through training, provision of better materials and equipment, in addition to inclusion of other diagnostic methods, e.g. culture services. Our sputum smearpositivity rate was lower than that reported from Ethiopia (43.0\%) (2), Spain (50.7\%) (7) and Nigeria (59.1\%) (10). Due to limited resources in our setting, culture services are not available. However, in our national reference laboratory sputum culture is offered to treatment failure cases to test for drug susceptibility. The radiological services exist only in large centres, therefore chest X-ray is used for diagnosis in a minority of patients.

In this study the sputum conversion rate to negative at the end of the initial phase of treatment was $61.9 \%$, compared with the WHO recommended rate of $90 \%$, indicating a good response to treatment. On the other hand, only $34.0 \%$ of patients completed treatment, well below the WHO target of $85 \%$. This is much lower than the figure reported from New York city in the United States of America (91\%) where factors associated with delay in treatment completion were attributed to poor communication, refusal to continue treatment and movement of patients from one site of care to another (11). Our default rate from treatment was $8.1 \%$, versus the WHO target of $4 \%$, and this is slightly lower than that the rate reported in a study in Nigeria (9.1\%) (10), but higher than a study in India (7.2\%) (12). Causes of default may include older age, smear-negativity, extrapulmonary tuberculosis, rural residence, HIV co-infection and longer treatment regimens (10).

The death rate during treatment was high in our study (8.0\%), compared with the WHO target of 3\%, and this may be due to the late presentation of patients or to improper patient care during treatment, as some patients may have a poor general state of health that needs correction before starting tuberculosis treatment. This death rate is higher than that reported in Ethiopia (6.3\%) (2), but lower than that reported from Nigeria (9.9\%) (10) and Singapore (11.0\%) (13). Special 


\begin{tabular}{|c|c|c|c|c|c|}
\hline \multirow[t]{2}{*}{ HIV status } & \multirow{2}{*}{$\begin{array}{l}\text { Total } \\
\text { No. }\end{array}$} & \multicolumn{2}{|c|}{$\begin{array}{c}\text { Cured/completed } \\
\text { treatment }\end{array}$} & \multicolumn{2}{|c|}{ Died } \\
\hline & & No. & $\%$ & No. & $\%$ \\
\hline Positive & 10 & 7 & 70.0 & 2 & 20.0 \\
\hline Negative & 254 & 213 & 83.8 & 16 & 6.3 \\
\hline Not tested & 957 & 718 & 75.0 & 85 & 8.9 \\
\hline
\end{tabular}

$P=0.002$ (chi-squared test).

consideration is needed for tuberculosis patients at the extremes of age, as the death rate was significantly higher in patients below 1 year and above 50 years of age. The death rate was slightly, but not significantly, higher in males than females (9.2\% versus $7.0 \%)$, a smaller sex difference than found in Japan (23.7\% for males and $18.9 \%$ for females) (14). The death rate among pulmonary tuberculosis cases was higher than among extrapulmonary cases (9.1\% versus $6.2 \%$ ), although the difference was not statistically significant, in contrast to data reported from Nigeria (10). Factors reported to be associated with lower survival rates include underweight, extra-pulmonary $\mathrm{TB}$, smear-negative pulmonary $\mathrm{TB}$, drug misuse, smoking, alcohol drinking and HIV co-infection $(2,10,15)$.

HIV testing is voluntary in our centres and only about one-fifth of tuberculosis patients volunteered to be tested for HIV, despite the WHO recommendation of $100 \%$. This can be explained by the stigma associated with HIV positivity in our community. Among those tested, 3.8\% of them tested positive. The mortality rate among HIV-positive tuberculous cases $(20.0 \%)$ was significantly higher than those testing HIV negative
(6.3\%) and those not tested (8.9\%). This finding is consistent with the reported death rate of $25.7 \%$ among HIV and tuberculosis co-infected patients in Ethiopia (16). It should be mentioned that HIV-positive cases in River Nile state receive antiretroviral therapy free of charge.

This study had some limitations. The records in the tuberculosis management units were not always complete, so some missing data were excluded from analysis. Being a health-facilitybased study does not allow generalizations to be made about the prevalence and incidence of tuberculosis in the community, especially considering the low public awareness about tuberculosis and high illiteracy rate in our community. Therefore, a nationwide survey is recommended to determine more accurately the tuberculosis prevalence in the community.

Despite of these limitations, we believe that this study is unique in its documentation and evaluation of the tuberculosis programme performance in north Sudan. It may serve as a model database for other states in Sudan, and similar developing countries. Similar reports from other states of Sudan will clarify the real situation in the country as a whole.
In conclusion, the burden of tuberculosis in River Nile state of Sudan is among young males and there is considerable delay in initiation of care. Moreover, all indicators assessing the control programme are lagging far behind the WHO required targets. Further studies to identify the causes of this poor performance are needed. More than one component of the health system that influence these indicators may be a focus for improvement. These include capacity-building of health personnel, improving the health system infrastructure, increasing public awareness and responding to needs and concerns of patients that have an impact on treatment compliance. In addition, legislation that makes case notification compulsory, enhancing surveillance and contact tracing may be steps in the right direction. Establishment of an electronic tuberculosis information system would help in data accessibility and analysis.

\section{Acknowledgements}

We thank the Ambassador of Switzerland to Sudan and the team working with him. Our thanks are extended to the team of the tuberculosis control programme especially Mrs Laila.

Funding: This work was supported by the Embassy of Switzerland in Khartoum (Small Action Fund, 2013). The donors had no role in study design, data collection, analysis or writing of the report. The authors alone are responsible for the data analysis and report writing.

Competing interests: None declared.

\section{References}

1. Global tuberculosis report 2015. Geneva: World Health Organization; 2015 (http://www.who.int/tb/publications/global_report/en/, accessed 20 December 2015).

2. Getahun B, Ameni G, Biadgilign S, Medhin G. Mortality and associated risk factors in a cohort of tuberculosis patients treated under DOTS programme in Addis Ababa, Ethiopia. BMC Infect Dis. 2011;11:127. PMID:21575187

3. Stop TB Partnership. Compendium of indicators for monitoring and evaluation national tuberculosis programs. Geneva: World Health Organization; 2004 (WHO/HTM/TB/2004.344) 
(http://apps.who.int/iris/bitstream/10665/68768/1/WHO HTM_TB_2004.344.pdf, accessed 20 December 2015).

4. Maher D, Mikulencak M. What is DOTS? A guide to understanding the WHO-recommended tuberculosis control strategy known as DOTS. Geneva: World Health Organization; 1999 (WHO/CDS/CP/tuberculosis/99.270).

5. Raviglione MC, Uplekar MW. WHO's new Stop tuberculosis strategy. Lancet. 2006 Mar18;367(9514):952-5. PMID:16546550

6. Global tuberculosis report 2014. Geneva: World Health Organization; 2014

7. Cruz-Ferro E, Ursúa-Díaz MI, Taboada-Rodríguez JA, HervadaVidal X, Anibarro L, Túñez V; Galician Tuberculosis Prevention and Control Programme Working Group. Epidemiology of tuberculosis in Galicia, Spain, 16 years after the launch of the Galician tuberculosis programme. Int J Tuberc Lung Dis. 2014 Feb;18(2):134-40. PMID:24429303

8. Boum Y 2nd, Atwine D, Orikiriza P, Assimwe J, Page AL, Mwanga-Amumpaire J, et al. Male gender is independently associated with pulmonary tuberculosis among sputum and non-sputum producers people with presumptive tuberculosis in Southwestern Uganda. BMC Infect Dis. 2014;14(1):638. PMID:25492725

9. Abdallah TM, Ali AAA. Epidemiology of tuberculosis in Eastern Sudan. Asian Pac J Trop Biomed. 2012 Dec;2(12):999-1001. PMID:23593582

10. Alobu I, Oshi SN, Oshi DC, Ukwaja KN. Risk factors of treatment default and death among tuberculosis patients in a resource- limited setting. Asian Pac J Trop Med. 2014 Dec;7(12):977-84. PMID:25479627

11. Bhavnani D, Lancki N, Winter I, Macaraig M. Treatment outcomes of patients with tuberculosis in New York city. J Public Health Manag Pract. 2014 Dec 30 PMID:25551205

12. Vasudevan K, Jayakumar N, Gnanasekaran D. Smear conversion, treatment outcomes and the time of default in registered tuberculosis patients on RNTCP DOTS in Puducherry, Southern India. J Clin Diagn Res. 2014 Oct;8(10):JC05-08. PMID:25478371

13. Chee CBE, Lim LKY, KhinMar KW, Han KY, Gan SH, Cutter J, et al. Surveillance of tuberculosis treatment outcomes of Singapore citizens and permanent residents, 2002-2011. Int J Tuberc Lung Dis. 2014 Feb;18(2):141-6. PMID:24429304

14. Uchimura K, Ngamvithayapong-Yanai J, Kawatsu L, Ohkado A, Yoshiyama T, Shimouchi A, et al. Characteristics and treatment outcomes of tuberculosis cases by risk groups, Japan, 2007-2010. Western Pac Surveill Response J. 2013 Jan;4(1):118. PMID:23908950

15. Ajagbe OB, Kabir Z, O'Connor T. Survival analysis of adult tuberculosis disease. PLoS One. 2014;9(11):e112838. PMID:25409024

16. Belayneh M, Giday K, Lemma H. Treatment outcome of human immunodeficiency virus and tuberculosis co-infected patients in public hospitals of eastern and southern zone of Tigray region, Ethiopia. Braz J Infect Dis. 2015 Jan-Feb;19(1):47-51. PMID:25467923 